Esta revista forma parte del acervo de la Biblioteca Jurídica Virtual del Instituto de Investigaciones Jurídicas de la UNAM

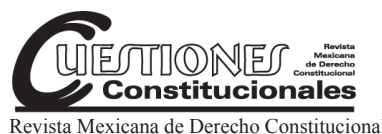

Núm. 37, julio-diciembre 2017

\title{
MECANISMOS ALTERNATIVOS DE RESOLUCIÓN DE CONFLICTOS: UN ACCESO A LA JUSTICIA CONSAGRADO COMO DERECHO HUMANO EN LA CONSTITUCIÓN MEXICANA
}

\author{
ALTERNATIVE DISPUTE RESOLUTION MECHANISMS: \\ AN ACCESS TO THE JUSTICE ENSHRINED AS A HUMAN \\ RIGHT IN THE MEXICAN CONSTITUTION
}

\author{
Wendolyne NAVA GONZÁLEZ* \\ Jorge Antonio BRECEDA PÉREZ**
}

RESUMEN: La Constitución federal mexicana, a partir de la reforma del artículo 17 del 18 de junio de 2008, introduce al orden jurídico nacional los mecanismos alternativos de resolución de conflictos como un derecho humano. Es así como la justicia alternativa alcanza su punto más alto, en virtud de que la norma constitucional la establece como obligatoria para todas las áreas del derecho. Siguiendo la directriz que señala la Constitución en la materia, el presente artículo a través un análisis crítico de la nueva Ley de Justicia Alternativa del Estado de Chihuahua, como caso de estudio, busca determinar si la normativa estatal garantiza un verdadero acceso a la justicia mediante los mecanismos alternativos de resolución de conflictos.

Palabras clave: mecanismos alternativos de resolución de conflictos, ADR, justicia alternativa, acceso a la justicia, derechos humanos, Constitución mexicana.
ABSTRACT: The Federal Constitution of the United Mexican States, since the reform of the article 17, in June 2008, introduced to the national legal order alternative dispute resolution mechanisms as a human right. Thus, alternative justice reaches its highest point, by virtue of the constitutional provision that establishes it mandatory for all areas of law. Following the guidelines established by the Constitution in this area, this article, through a critical analysis of the new Law of Alternative Justice in the State of Chihuahua as a case study, seeks to determine whether state regulations guarantee real Access to justice through alternative dispute resolution mechanisms.

Key words: alternative dispute resolution mechanisms, ADR, alternative justice, access to the justice, human rights, mexican Constitution.

* Doctora en Derecho por la Universidad de Barcelona; profesora-investigadora de la Universidad Autónoma de Ciudad Juárez; integrante del Centro Investigaciones Jurídicas de la UACJ. Correo electrónico: wendolyne.nava@uacj.mx

** Doctorando de la Universidad de Barcelona; profesor-investigador en la Universidad Autónoma de Ciudad Juárez; miembro del Centro de Investigaciones Jurídicas en la UACJ. Correo electrónico:jorge.breceda@uacj.mx 
Esta revista forma parte del acervo de la Biblioteca Jurídica Virtual del Instituto de Investigaciones Jurídicas de la UNAM

SUMARIO: I. Introducción. II. Acceso a la justicia. III. El papel de los mecanismos alternativos de resolución de conflictos en la impartición de justicia: ventajas e inconvenientes. IV. Análisis crítico de la Ley de Justicia Alternativa del Estado de Chihuahua (caso de estudio). V. Reflexiones finales.

VI. Bibliografía.

\section{INTRODUCCIÓN}

Cualquier Estado democrático en el que se establezca un discurso en pro hacia los derechos humanos forzosamente deberá contar con instituciones encargadas de que cada miembro de la sociedad tenga la potestad de acceder a la justicia. Los mecanismos alternativos de resolución de conflictos, ${ }^{1} \mathrm{o}$ también conocidos por sus siglas en inglés como ADR, ${ }^{2}$ surgen precisamente de la imperiosa necesidad de modernizar el sistema tradicional de justicia, con el objetivo claro de ofrecer al ciudadano una opción simple, rápida y económica de solucionar sus conflictos.

Así, México tiene una larga trayectoria en relación a estos procedimientos alternativos de solución de conflictos, específicamente, en materia laboral y de defensa del consumidor. Sin embargo, la incorporación de los ADR al Poder Judicial de los estados se dio por primera vez en Quintana Roo en 1997, cuando se publicó la Ley de Justicia Alternativa y en consecuencia se creó el primer Centro de Asistencia Jurídica, un órgano desconcentrado del Poder Judicial, cuyo objetivo primordial era que los particulares resolvieran sus controversias de carácter jurídico de naturaleza exclusivamente privada; por lo que es importante destacar que muchas de las entidades federativas siguieron el ejemplo de Quintana Roo, al implementar una ley de justicia alternativa y crear instituciones pertenecientes al Poder Judicial para ofrecer servicios de mediación y conciliación.

Un ejemplo es el de Guanajuato, después de una importante reforma a la Constitución ${ }^{3}$ de esa entidad federativa en 2003, en mayo de ese mismo año se publica la Ley de Justicia Alternativa, que regula los procedimientos

1 Entre los que se incluye la negociación, la mediación, la conciliación y el arbitraje.

2 ADR: siglas en inglés para Alternative Dispute Resolution.

3 Se reforman los artículos 3o. y 89 de la Constitución Política para el Estado de Guanajuato. 
Esta revista forma parte del acervo de la Biblioteca Jurídica Virtual del Instituto de Investigaciones Jurídicas de la UNAM

de mediación y conciliación bajo los principios de equidad, imparcialidad, rapidez, profesionalismo y confidencialidad. En noviembre del 2003 entra en funcionamiento el Centro de Justicia Alternativa con cinco Sedes Regionales en las principales ciudades del estado; para 2005 había ocho en funcionamiento, convirtiéndose así en un referente a nivel nacional.

No obstante, a pesar de los esfuerzos legislativos de los estados a favor de los ADR, estos mecanismos no lograron consolidarse de la forma esperada. Fue hasta la reforma del artículo 17 de la Constitución federal en 2008 que señala: "Las leyes preverán mecanismos alternativos de solución de controversias", que los ADR cobraron un renovado protagonismo en el país, en virtud de que se reconoce por primera vez como derecho humano la posibilidad de que sean las partes las que resuelvan su conflicto sin necesidad de que el Estado intervenga de forma directa. Tras esta importante reforma constitucional, el Poder Judicial federal manifestó que tanto la tutela judicial como los mecanismos alternos de solución de controversias se encuentran en un mismo plano constitucional, con la misma dignidad y con idéntica finalidad: solucionar conflictos. ${ }^{4}$

Ahora bien, la modificación constitucional del artículo 17, publicada en el Diario Oficial de la Federación el 18 de junio de 2008 - cuyo artículo 2o. transitorio fijó un plazo de ocho años contados a partir del siguiente día de su publicación para su implementación - provocó que prácticamente todos los estados de la República mexicana incorporaran ADR, a través de sus poderes judiciales locales, para la solución de conflictos familiares, civiles, mercantiles e incluso penales, cimentando así una verdadera política pública a favor de los mecanismos alternos de solución de conflictos. ${ }^{5} \mathrm{~A}$ la fecha sólo Guerrero no cuenta con una ley de esta naturaleza.

Sin embargo, surge la pregunta de ¿si en realidad estas leyes e instituciones están diseñadas y desarrolladas para garantizar a la población un verdadero acceso a la justicia en los términos que lo plantea la Constitución? En base a lo anterior, el desarrollo de este trabajo contempla su división de la siguiente manera: como punto de partida se tratarán las características básicas que definen el paradigma de acceso a la justicia, así como también los aspectos teóricos, doctrinales y jurídicos más relevantes de los ADR, a

4 Tesis III.2o. C.6 K, Semanario Judicial de la Federación y su Gaceta, Décima Época, Libro XXV, octubre de 2013, p. 1723.

5 Gorjón, Francisco, "Implementación de las reformas al artículo 17 constitucional en materia de MASC en México y Panamá”, Letras Jurídicas, núm. 11, 2010, p. 2. 
Esta revista forma parte del acervo de la Biblioteca Jurídica Virtual del Instituto de Investigaciones Jurídicas de la UNAM

fin de establecer las bases idóneas del deber ser de su regulación, diseño e instrumentación. A partir de ese abordaje conceptual se hará un análisis de la realidad jurídica de esa estructura tomando como referencia el examen crítico de la Ley de Justicia Alternativa del Estado de Chihuahua, como estudio de caso, a fin de determinar si la normativa cumple con las expectativas de la Constitución federal en la materia.

\section{ACCESO A LA JUSTICIA}

A razón de contextualizar en relación al tema de acceso a la justicia, se presentarán de forma sistemática los elementos básicos que la caracterizan desde el punto de vista teórico-dogmático, tomando como base el significado que la doctrina le otorga a esta institución.

\section{Acceso a la justicia como concepto}

Resulta indispensable colocar un par de interrogantes de manera directa: ¿a qué se refiere la construcción conceptual de acceso a la justicia? ¿Cuáles son las propuestas institucionales sobre la definición de dicho término?

Una de las definiciones mas claras al respecto la establece el Instituto Interamericano de Derechos Humanos, al señalar que: "Es la posibilidad de que cualquier persona independientemente de su condición, tenga la puerta abierta para acudir a los sistemas de justicia, si así lo desea, a mecanismos e instancias para la determinación de derechos y la resolución de conflictos". ${ }^{6}$ Con base en lo anterior, resulta lógico observar el acceso a la justicia como un derecho fundamental, ya que implícita e inherentemente promueve directrices de igualdad, no discriminación y acceso al conocimiento de los derechos y equidad jurisdiccional.

A partir de lo antes expuesto, el acceso a la justicia se puede analizar como la potestad individual o colectiva de cualquier miembro o comunidad de la sociedad — con independencia de desigualdades sociales y económicas - de acudir a instituciones estatales y paraestatales que administran justicia para una defensa digna durante el procedimiento judicial; mismas que deberán de garantizar una resolución basada en los preceptos de in-

6 Instituto Interamericano de Derechos Humanos, Guía informativa, XVIII Curso interdisciplinario de derechos humanos, IIDH, San José, Costa Rica, 2000, p. 17. 
Esta revista forma parte del acervo de la Biblioteca Jurídica Virtual del Instituto de Investigaciones Jurídicas de la UNAM

mediatez, transparencia, autonomía, objetividad, no onerosidad e imparcialidad. Es trascedente mencionar que las instituciones no se limitan a estructuras nacionales o locales, sino que tienen un ámbito extraterritorial (respecto al Estado), al observar tribunales, cortes y comisiones a nivel internacional.

Hasta este momento, hablar de acceso a la justicia necesariamente lleva presupuestos inherentes en su quehacer como lo son: $i$ ) renuncia del individuo a la venganza privada; $i i$ ) existencia de instituciones, públicas o privadas, encargadas de la administración de justicia; iii) legislaciones tanto adjetivas como instrumentales; $i v$ ) jurisdicciones plenamente identificables; $v$ ) resoluciones o acuerdos legítimos a las controversias planteadas; vi) jueces o terceros competentes e imparciales, dentro de un marco jurídico determinado, y $v$ ) derecho a una defensa otorgada por el Estado.

Para concluir con este orden de ideas es necesario distinguir tres de las muchas implicaciones que sostienen el acceso a la justicia como construcción jurídica para los estados:

- Primero, respecto a su conformación material, las instituciones deberán diseñarse e implementarse con el objetivo claro de garantizar a la población que se encuentran al alcance de todos.

- Segundo, en el ámbito social del acceso a la justicia es indispensable crear mecanismos mercadológicos — marketing gubernamental - con los que se construya una campaña en la que se den a conocer los mecanismos e instituciones jurisdiccionales a los que las personas pueden acceder; a fin de lograr un posicionamiento en la población y con ello se pueda crear y acuñar una realidad social y que ésta se fije en la mentalidad de la población.

- Tercero, el tópico que nos ocupa es, sin duda, un tema de legitimación para cualquier Estado democrático, ya que hablar de acceso a la justica requiere promover la idea de un derecho humano instrumental, una prerrogativa que debe de encontrarse en el quehacer jurisdiccional y en las políticas públicas que sostienen al Poder Judicial. Promover este derecho permitiría observar un estado en el que la legislación no sólo suscribirá la idea de personas iguales, sino crearía un lente en el que los individuos se observen en un plano de equidad no solamente en la impartición de justicia, sino en la vida económica, política y social. 
Esta revista forma parte del acervo de la Biblioteca Jurídica Virtual del Instituto de Investigaciones Jurídicas de la UNAM

\section{Acceso a la justicia y los mecanismos alternativos de resolución de conflictos}

A partir de lo expuesto hasta el momento, se puede inferir que el acceso a la justicia constituye un derecho inherente del individuo, razón por la cual es trascendente que el Estado mexicano - doblemente obligado- construya los mecanismos mínimos para materializar el multicitado derecho, así como políticas públicas de diversa índole que intrínsecamente refieran al derecho aquí sustentado, y un sistema de planeación y evaluación de las instituciones judiciales para hacer medible esta prerrogativa ciudadana. Cabe mencionar que en una suerte de paralelismo, el ciudadano podrá demandarle al Estado su obligación de promover y accionar políticas de acceso a la justicia, ya que se encuentran claramente consagradas en el sistema jurídico.

Es por ello que el acceso a la justicia constituye un derecho concebido de manera trascendental, pues en un imaginario en el que no existiera nos encontraríamos en un escenario de esterilidad estatal. La reflexión va en el sentido de que es impensable construir una idea de prerrogativas fundamentales sin la existencia (previa) de un sistema jurídico que defienda los anteriores, en el cual se pondere la facultad de la participación del ciudadano.

Es importante mencionar que en un análisis normativo nos encontramos con un modelo jurídico que recobra importancia, ya que permite configurar el derecho del acceso a la justicia y brinda la oportunidad al Estado mexicano de cumplir con lo que jurídica y socialmente se encuentra obligado, nos referimos a la aparición de los mecanismos de solución alternativa, dispositivos jurisdiccionales que surgen para consolidar el acceso a la justicia de forma eficiente y cercana a las necesidades de la población.

Sin embargo, el problema con los ADR seguirá persistiendo para efectos de derechos humanos si realmente no se crean herramientas para acortar la distancia entre el acceso a la justicia y la población, llámense: cuestiones geográficas, físicas, sociales, económicas, psicológicas y, por supuesto, normativas. A partir de aquí el balance entre los mecanismos mencionados y el acceso a la justicia se torna complejo, razón por la cual se desarrollarán a continuación los elementos que contienen los ADR y sus implicaciones en el acceso a la justicia. 
Esta revista forma parte del acervo de la Biblioteca Jurídica Virtual del Instituto de Investigaciones Jurídicas de la UNAM

\section{EL PAPEL DE LOS MECANISMOS ALTERNATIVOS}

DE RESOLUCIÓN DE CONFLICTOS EN LA IMPARTICIÓN DE JUSTICIA:VENTAJAS E INCONVENIENTES

El término justicia alternativa se puede entender como "una estructura procesal distinta de la jurisdiccional para la solución de controversias entre particulares"7 a través de los llamados mecanismos alternativos de solución de conflictos. Como ya se ha apuntado, los métodos clásicos de resolución de conflictos son la negociación, la mediación, la conciliación y el arbitraje.

Así, resulta necesario partir de una definición o descripción legal de estos mecanismos a fin de identificar de forma objetiva sus elementos estructurales, ratio de su existencia, ventajas e inconvenientes.

Los ADR son: “...una gama de procedimientos que sirven como alternativas a los procedimientos adjudicativos de litigio para la solución de controversias, que por lo general, aunque no necesariamente involucran la intercesión y asistencia de un tercero neutral que ayuda a facilitar dicha solución". 8

En otras palabras, se puede decir que los medios alternativos de solución de conflictos constituyen mecanismos convencionales, expeditos y económicos de solución de controversias; incluyen: $i$ ) los sistemas de negociación que buscan crear un ambiente que permitan a las partes alcanzar una solución razonable por sí mismos; $i$ ) se extienden a los sistemas que cuentan con la intervención de un tercero ajeno a la disputa, que auxiliando (mediación) o proponiendo ( conciliación) coopera para que éstas lleguen a un acuerdo por ellas mismas, y iii) alcanza a las modalidades adversariales a través de las cuales el tercero decide o resuelve (arbitraje).

A pesar de que estos mecanismos son muy diversos presentan características similares: son métodos menos formales - lo cual no significa que no sean estructurados - que los judiciales; ofrecen mayores posibilidades a las partes de participar activamente y de controlar de forma más cercana el proceso de solución de sus conflictos que los métodos tradicionales; la

7 Mondragón, Fabián, "Justicia alternativa en materias civil, mercantil y familiar", en Ferrer, Eduardo (comp.), Procesalismo cientifico. Tendencias contemporáneas, México, UNAM, Instituto de Investigaciones Jurídicas, 2012, p. 109.

8 Estalvillo, Fernando, Medios alternativos de solución de controversias, México, Porrúa, 2004, p. 66. 
Esta revista forma parte del acervo de la Biblioteca Jurídica Virtual del Instituto de Investigaciones Jurídicas de la UNAM

mayoría de estos mecanismos se han desarrollado en el sector privado, aunque los órganos administrativos y los tribunales empiezan a introducirlos a nivel intraprocesal.

Cabe destacar que las particularidades básicas de estos sistemas alternos radican en que a las partes involucradas proveen en un litigio la oportunidad de resolverlo de una manera rápida, económica, flexible y efectiva, encontrando el procedimiento que mejor se adapta a sus necesidades y circunstancias particulares. Además, estos sistemas se rigen por principios como: la confidencialidad, neutralidad, imparcialidad, independencia, colaboración y voluntariedad, por destacar los más importantes.

Se ha dicho que los ADR ponen en jaque el monopolio exclusivo del Poder Judicial en la impartición de justicia, ${ }^{9}$ lo cierto es que han encontrado la manera de coexistir y complementarse.

\section{Justificación para la creación de los ADR}

Ahora bien, diversos autores han establecido motivaciones concretas que justifican la reaparición de mecanismos alternativos de resolución de conflictos en las últimas décadas. Por otro lado, hay quienes afirman que estos procedimientos extrajudiciales han surgido simplemente como una opción más con la que el gobernado cuenta para zanjar sus controversias, sin que medie razón alguna que justifique su presencia.

Entre los autores que defienden esta última hipótesis podemos destacar a Ramos Méndez, refiriéndose a la resolución de conflictos en el ámbito civil patrimonial en España, quien sostiene que aun cuando el Poder Judicial tiene el monopolio de la resolución de conflictos, esto no impide que se busquen soluciones alternativas y que éstas se utilicen en sectores en los cuales impera la autonomía de la voluntad, es decir, que es posible una concurrencia de servicios, de tal manera que, asimismo, de los servicios públicos de justicia puede haber otros servicios completamente privados, dándose así una competición de servicios de justicia. Entre sus conclusiones afirma que la opción por estas modalidades dimana de la voluntad de las partes, como vía electiva ante el sistema judicial ordinario, nada más;

\footnotetext{
9 Cervantes, Irina, "La justicia alternativa en la Constitución de Cádiz de 1812 y su influencia en el constitucionalismo mexicano", en López, Eduardo et al., La Constitución de Cádiz de 1812 y su impacto en el occidente novohispano, México, UNAM, Instituto de Investigaciones Jurídicas, 2015, p. 514.
} 
Esta revista forma parte del acervo de la Biblioteca Jurídica Virtual del Instituto de Investigaciones Jurídicas de la UNAM www.juridicas.unam.mx https://biblio.juridicas.unam.mx/bjv DOI: http://dx_doi.org/10.22201/iij.24484881e.2017.37.11457

https://revistas.juridicas.unam.mx

MECANISMOS ALTERNATIVOS DE RESOLUCIÓN DE CONFLICTOS...

así las cosas, pareciera que todo se reduce a una simple concurrencia de servicios, cuya única motivación es el capricho de tener otras opciones además de las que el sistema tradicional ofrece. ${ }^{10}$

Por otro lado, hay quienes afirman también que cuando se buscan alternativas hay una necesidad o un problema que lo motiva; diferentes autores ${ }^{11}$ aseguran que la verdadera motivación para la implementación de ADR es la crisis en la administración de justicia.

Lo cierto es que toda persona tiene derecho a que se le administre justicia por tribunales expeditos. Las resoluciones se deben dictar de manera pronta, completa e imparcial y lo ideal es que el servicio sea gratuito, en otras palabras, que el libre acceso a la justicia debe ser transparente, autónomo, independiente y equitativo, sin dilaciones indebidas ni formalismos o reposiciones inútiles; sin embargo, en la mayoría de los casos esto no sucede, por las razones que a continuación se señalan.

Primero, los procesos judiciales por lo general son lentos, se sostiene que endémicamente en algunos estados la capacidad de oferta judicial es superada por la demanda, problema que no se solucionaría ni siquiera con

10 Ramos, Fernando, Medidas alternativas a la resolución de conflictos por la vía judicial en el ámbito civil patrimonial, España, Bosch, 1981, pp. 811 y 812.

11 Linda Singer en su libro Resolución de conflictos, Buenos Aires, Paidós, pp.12-29, hace una reseña muy completa sobre como la adopción de las ADRS es resultado de la crisis en la administración de justicia en los Estados Unidos. Silvia Barona en su libro Solución extrajurisdiccional de conflictos y derecho procesal, Valencia, Tirant lo Blanch, 1999, p. 171, señala refiriéndose al caso Español que: “...el sistema de la justicia estatal está en crisis, ciertamente como fenómeno global y universal... La asunción de la ADR es resultado, uno más, de la globalización como fenómeno de la realidad socioeconómica de la segunda mitad del Siglo XX. No es malo movilizarse en la búsqueda de fórmulas, medios, técnicas que consigan efectivizar la justicia." Asimismo, El libro verde sobre modalidades alternativas de solución de conflictos en el ámbito civil y mercantil, COM, 2002, 196 final, p. 6, señala: "Desde hace algunos años se asiste a los Estados miembros al desarrollo de las modalidades llamadas alternativas de solución o de resolución de conflictos, aunque todo el mundo esté de acuerdo que estos sistemas son muy antiguos. Las ventajas inherentes a estas modalidades de justicia privada y la crisis de eficacia de los sistemas judiciales suscitaron un interés renovado hacia estos métodos de apaciguamiento de los conflictos más consensuales que el recurso al juez o a un árbitro". Por otro lado, El Consejo Permanente de la Organización de los Estados Americanos, en un documento denominado Métodos alternativos de resolución de conflictos en los sistemas de justicia de los países americanos, OEA/Ser.K/XXXIV.4, REMJA-IV/DOC.13/02. 2010, p. 4, refiriéndose al establecimiento de ADRS en los países americanos dice: "Los Objetivos directos más expuestos entre los argumentos gubernamentales han sido la necesaria descongestión de los tribunales, la mayor celeridad en el conocimiento y resolución de las contiendas y el necesario mejoramiento del acceso a la justicia". 
Esta revista forma parte del acervo de la Biblioteca Jurídica Virtual del Instituto de Investigaciones Jurídicas de la UNAM

la creación de nuevos tribunales o el incremento de la plantilla de recursos humanos en los juzgados. ${ }^{12}$ Asimismo, aún en los sistemas judiciales más desarrollados, la propia naturaleza de los procesos y las formalidades que se imponen para garantizar la libre defensa en juicio suponen una inevitable dilación temporal respecto de la resolución definitiva del conflicto por esta vía.

Segundo, los asuntos legales se caracterizan por sus altos costos. En algunos Estados existe el defensor de oficio para garantizar a todos el acceso a la justicia de manera gratuita, sin embargo, en la práctica se presenta cierta desconfianza a esta figura por parte del ciudadano, debido a la cantidad excesiva de asuntos que maneja y el poco salario que percibe, esto trae como resultado que se recurra a servicios profesionales, lo cual implica altos honorarios.

Tercero, la creciente complicación y proliferación de leyes, con la conexa complejidad de problemas inherentes a su aplicación. Se incrementan las dificultades cuando la nacionalidad de los contendientes es diversa, pese a la existencia de convenios internacionales, las dificultades que surgen en la vía judicial — conflicto de leyes y de órganos jurisdiccionales, dificultades prácticas de tipo lingüístico y financiero - disuaden a las partes en conflicto de reclamar ante los tribunales el cumplimiento efectivo de sus derechos.

En conclusión, si bien es cierto que el sistema de justicia tradicional, en términos generales, presenta algunas deficiencias, también lo es que los ADR en ningún momento buscan sustituirlo. Por el contrario, su objetivo primordial es complementar en virtud de que existen ciertos tipos de controversias, en las cuales estos mecanismos alternos son idóneos para su resolución y, por lo tanto, representan una alternativa más con la que cuentan las personas para la solución de sus conflictos.

\section{ADR: ventajas e inconvenientes}

Los beneficios derivados de la utilización de los ADR son muchos y muy variados. En resumen podemos decir que las principales ventajas de los procedimientos alternativos, a partir de su comparación con la vía judicial

12 Vargas, Juan, "Problemas de los sistemas alternos de resolución de conflictos como alternativa de política pública en el sector judicial," Anales de Jurisprudencia, 264, julioagosto de 2003, p. 229. 
Esta revista forma parte del acervo de la Biblioteca Jurídica Virtual del Instituto de Investigaciones Jurídicas de la UNAM

tradicionalmente utilizada para dirimir conflictos, son las siguientes: son más rápidos, menos onerosos, privados y confidenciales; se desarrollan en un entorno y un clima adecuados para el tratamiento del conflicto; y brindan a los participantes la posibilidad de gestionar su propio acuerdo.

En estos mecanismos no todo son ventajas. Muchas de las críticas que se vierten a los sistemas alternativos de resolución de conflictos son proporcionados paradójicamente por quienes los apoyan. Entre los argumentos en contra podemos destacar los siguientes: $:^{13}$

Se les critica por favorecer a los poderosos, es decir, a quienes se les percibe con una mejor posición negociadora. De hecho, existe una ardua controversia sobre si las negociaciones informales son aconsejables cuando las partes en litigio están en una situación de evidente desigualdad de poderes, como es el caso de consumidor y empresa, ya que, en ocasiones, se terminan produciendo resultados injustos. En este mismo sentido, se opina que la amplia libertad para alcanzar soluciones que caracteriza a los ADR distorsiona la voluntad del legislador.

Otro de los argumentos en contra señala que estos mecanismos no crean precedente alguno, de modo que puede suceder, que una vez se resuelva en un sentido y a la siguiente ocasión se resuelva en otro.

Además, se arguye que con ellos se lesiona el derecho a la defensa, sobre todo cuando se los acepta sin la intervención de personas especializadas asesorando a las partes y con mediadores en ocasiones sin formación jurídica.

Entre sus críticas se encuentra aquella que afirma que estos sistemas no son aceptables, pues no constituyen más que una "justicia de segunda clase" a la que accede el Estado por su incapacidad de promover para todos una justicia de primer nivel.

Algunos de estos argumentos son en cierta manera válidos, con otros simplemente no coincidimos. Lo cierto es que los ADR no siempre son un mecanismo aplicable y en todos los ámbitos, tampoco es una panacea que resuelva todos los problemas de la administración de justicia. Además, existe aún la incertidumbre en relación al papel del Estado con respecto de estos sistemas ya que, para algunos, el Estado debe intervenir activamente, no sólo promoviendo dichos mecanismos, sino también legislando, y proveyendo servicios alternativos de justicia, en general, a la comunidad y para otros el Estado debe alejarse de ellos, pues su intervención los desnaturaliza completamente.

13 Vargas, Juan, op. cit., p. 237. 
Esta revista forma parte del acervo de la Biblioteca Jurídica Virtual del Instituto de Investigaciones Jurídicas de la UNAM

Pese a que estos sistemas en ocasiones dan la impresión de ser una promesa más que una realidad o que no han logrado consolidarse, es innegable, sin embargo, que pueden contribuir a garantizar un verdadero acceso a la justicia complementando al sistema de justicia tradicional.

\section{ANÁLISIS CRÍTICO DE LA LEY DE JUSTICIA ALTERNATIVA DEL ESTADo DE CHIHUAHUA (CASO DE ESTUdio)}

Hemos estado hablando del tema de acceso a la justicia y cómo los mecanismos alternativos de resolución de conflictos son una opción más con la que el ciudadano cuenta para resolver sus conflictos. A continuación se hará un análisis crítico de la Ley de Justicia Alternativa del Estado de Chihuahua, como caso de estudio, a fin de determinar si realmente estos mecanismos alternos garantizan un verdadero acceso a la justicia.

\section{Ley de Justicia Alternativa del Estado de Chihuahua}

Es de considerar, como antecedente, el intento fallido por implementar en el estado de Chihuahua los mecanismos alternativos de resolución de conflictos con sede judicial, tal como se venía haciendo en otras entidades federativas, por lo que se expidió en 2003 una Ley de Mediación, la cual crea el Centro Estatal de Mediación, órgano desconcentrado del Poder Judicial del estado, que nunca entró en funcionamiento. No forma parte de este artículo determinar el por qué no fue exitoso este primer esfuerzo, además no es una cuestión que pueda contestarse a priori, o que pueda responderse en base a posturas ideológicas o impresiones personales, digamos que simplemente no se consolidó.

Lo cierto es que a más de una década del fracaso de la Ley de Mediación $\mathrm{y}$, en consecuencia, del Centro Estatal de Mediación, y tras la multicitada reforma constitucional de 2008, el 29 de octubre de 2014, se publica la nueva Ley Orgánica del Poder Judicial del Estado de Chihuahua, la cual en su capítulo segundo establece la creación del Instituto de Justicia Alternativa, como órgano desconcentrado del Poder Judicial, concediéndole según lo establece el artículo 176: "Capacidad técnica para fomentar y promover los mecanismos alternativos de solución de controversias y la cultura de la paz, así como para otorgar los servicios propios de la materia, solicitados por las 
Esta revista forma parte del acervo de la Biblioteca Jurídica Virtual del Instituto de Investigaciones Jurídicas de la UNAM

personas físicas y morales, o bien, aquellos que le sean encomendados por los órganos jurisdiccionales en materia civil, mercantil, familiar y penal." Los artículos siguientes establecen que el Instituto tendrá competencia en todo el territorio del estado y que además sus servicios serán orales, confidenciales, voluntarios y gratuitos.

Estas disposiciones dieron pie a sugerir que la Ley de Mediación era insuficiente para regular las atribuciones que la Ley Orgánica del Poder Judicial concedía al Instituto de Justicia Alternativa, por lo que el paso lógico era abrogar la Ley de Mediación y crear una nueva. Esto sucedió el 25 de marzo de 2015, cuando se expide la Ley de Justicia Alternativa del Estado de Chihuahua, publicada en el Periódico Oficial del Estado el 30 de mayo de 2015, mediante decreto 873/2015 II P.O., entrando en vigor al siguiente día de su publicación.

\section{Análisis de la Ley de Justicia Alternativa del Estado de Chihuahua}

A continuación se hará un análisis crítico de la Ley, a partir de lo que la doctrina y diversos instrumentos internacionales establecen en la materia, lo cual se expone a continuación de la siguiente manera:

\section{A. Principio de la no discriminación}

El principio de la no discriminación, que se encuentra reflejado en el artículo 3o. establece que "todos los habitantes del estado tienen derecho a utilizar mecanismos alternativos para la solución de controversias" y se refuerza en el artículo 35, segundo párrafo, el cual señala que "los convenios o acuerdos que deriven de un mecanismo alternativo deberán elaborarse en estricto apego al derecho humano de la igualdad y la no discriminación." Como ya quedó asentado con anterioridad, no sólo existe en el estado de Chihuahua, sino en el país, una imperiosa necesidad de establecer una verdadera garantía de acceso a la justicia para los sectores más vulnerables de nuestra sociedad, ${ }^{14}$ un ejemplo claro, en el caso particular del estado de

14 González, Nuria, "Un acercamiento al acceso a la justicia a través de la mediación como medio alterno de solución de conflictos", en Flores, Elvia (comp.), Sin derechos, exclusión y discriminación en el México actual, México, UNAM, Instituto de Investigaciones Jurídicas, 2014, p. 113. 
Esta revista forma parte del acervo de la Biblioteca Jurídica Virtual del Instituto de Investigaciones Jurídicas de la UNAM

Chihuahua, es la comunidad Tarahumara o Rarámuri. A pesar de los esfuerzos gubernamentales que se han realizado en los últimos años, sigue siendo un sector excluido y marginado, especialmente en el tema de acceso a la justicia, y tal como lo señala Nuria González, si a eso agregamos el hecho de que no hablan castellano, además de su condición social y económica, esta combinación produce no sólo "una violación sistemática de sus derechos humanos", sino que además sus circunstancias particulares les hace casi imposible hacer valer sus derechos jurídicos a través de órganos jurisdiccionales tradicionales, en los términos del artículo 2o. constitucional, ${ }^{15}$ ya que por lo general los procesos ante tribunales son complejos, costosos, lentos y con un exceso de formalismo y burocracia.

En este orden de ideas, el hecho de que la ley se alineé a la Constitución federal y local en el tema de la no discriminación, nos parece bastante acertado. Es de destacar que el recién creado Instituto de Justicia Alternativa se toma bastante en serio está disposición y ha redactado un convenio con la Coordinación Estatal de la Tarahumara, en virtud del cual se ha capacitado a su personal que habla el dialecto de esta comunidad, en temas de justicia alternativa, con el objetivo de que sirva de intérprete en caso de necesitarlo. Asimismo tiene convenios con centros de lenguas de diversas instituciones académicas, ${ }^{16}$ para el caso de que cuando algún extranjero solicite los servicios que el Instituto de Justicia Alternativa provee, el idioma no sea un obstáculo. Sin embargo, aún queda mucho camino por recorrer.

\section{B. Objetivos de la Ley}

Otro punto a destacar lo encontramos en los objetivos de la Ley, los cuales se plantean en el artículo 2o. del ordenamiento jurídico. Entre ellos están: "restauración de las relaciones interpersonales y sociales"; "promover y regular la aplicación de mecanismos alternativos para la prevención y en su caso, la solución de controversias"; "regular la creación de centros,

15 El artículo 2o. constitucional en el apartado A, fracción VIII, señala: “Acceder plenamente a la jurisdicción del Estado. Para garantizar ese derecho, en todos los juicios y procedimientos en que sean parte, individual o colectivamente, se deberán tomar en cuenta sus costumbres y especificidades culturales respetando los preceptos de esta Constitución. Los indígenas tienen en todo tiempo el derecho a ser asistidos por intérpretes y defensores que tengan conocimiento de su lengua y cultura".

16 Se ha realizado convenio con la Universidad Autónoma de Chihuahua y la Universidad Autónoma de Ciudad Juárez. 
Esta revista forma parte del acervo de la Biblioteca Jurídica Virtual del Instituto de Investigaciones Jurídicas de la UNAM

en sede judicial y privados, que brinden los servicios previstos en este ordenamiento".

Coincidimos en que la esencia de la justicia alternativa va más allá de simplemente solucionar conflictos, tal como lo expresa la Suprema Corte de Justicia de la Nación, en jurisprudencia, estos mecanismos: "Propician una participación más activa de la población para encontrar otras formas de relacionarse entre sí, donde se privilegie la responsabilidad personal, el respeto al otro y la utilización de la negociación y la comunicación para el desarrollo colectivo". ${ }^{17}$ No es una tarea fácil, se tienen que romper paradigmas importantes a fin de lograr estos objetivos, pero definitivamente se están dando los pasos necesarios para que así sea.

Ahora bien, no podemos ignorar el hecho de que existe todavía mucha resistencia en la aplicación de estos mecanismos y sus alcances, sobre todo por parte de la comunidad de abogados. Nos parece bastante inteligente que la ley prevea la opción de que los particulares, ${ }^{18}$ específicamente licenciados en derecho, puedan crear centros de mediación privados para proporcionar estos servicios. Creemos que de ser así, contribuirá significativamente a lograr los objetivos de la ley, ya que ayudará a cambiar el concepto de que el Estado posee el monopolio para dirimir conflictos, por la idea de que en algunos casos las partes son dueñas de su propio litigio y, por lo tanto, son ellas quienes deben decidir la forma de resolverlo, con todo lo que esto conlleva.

Dicho lo anterior, resulta muy decepcionante que la ley plantee, ${ }^{19}$ como uno de los propósitos de los mecanismos alternos: "El evitar la apertura de procesos judiciales y el poner fin a los ya iniciados". Sin bien es cierto que en el primer párrafo citado del artículo respalda los objetivos planteados por la ley, también lo es que tal como se encuentra redactado el segundo párrafo, pareciera que uno de los objetivos de los ADR en relación a esta ley, sea disminuir el trabajo de los tribunales.

Sólo el tiempo dirá si de cumplirse la finalidad de la Ley de Justicia Alternativa para el Estado de Chihuahua, en los términos planteados, traerá como resultado la reducción de trabajo en los órganos jurisdiccionales, si lo hace será únicamente como un efecto colateral; sin embargo, estamos

17 Tesis PC.III.P.J/1P, Semanario Judicial de la Federación, Décima Época, 30 de mayo de 2014.

18 Artículo 8o. de la Ley de Justicia Alternativa del Estado de Chihuahua.

19 Artículo 9o. de la Ley de Justicia Alternativa del Estado de Chihuahua. 
Esta revista forma parte del acervo de la Biblioteca Jurídica Virtual del Instituto de Investigaciones Jurídicas de la UNAM

convencidos que no debería establecerse como un propósito de estos sistemas extrajudiciales, simplemente porque desvirtúa completamente su esencia. Debe quedar muy claro que los $A D R$ se plantean como una opción más con la que cuenta el ciudadano para resolver sus conflictos de una forma fácil, rápida, económica y flexible, complementando así el sistema tradicional de justicia; en otras palabras su finalidad primordial no sólo es garantizar, sino facilitar y mejorar el acceso a la justicia ${ }^{20}$ de todos los ciudadanos.

\section{C. Ámbito de aplicación}

Siguiendo con el análisis crítico de la Ley, resulta bastante confuso que la normativa en comento no establezca de forma expresa su ámbito de aplicación y, en consecuencia, sus limitaciones. Cabe mencionar que algunos artículos de la Ley nos ayudan a vislumbrarlo, como lo son el artículo 4o. en la parte en la que define qué es un acuerdo y un convenio, estableciendo que el primero se aplica a la materia penal y el segundo a la materia civil y familiar; luego tenemos el artículo 30, que se refiere al procedimiento, en una lamentable redacción del mismo, establece que el proceso se puede iniciar a petición de parte o por derivación de los jueces en materia civil, familiar y penal. Con base a lo anterior, se puede inferir que el ámbito de aplicación de la Ley es la materia civil, familiar y penal; sin embargo, en lo que respecta a las limitaciones, es decir, qué ámbitos quedan excluidos en la aplicación de la Ley, la normativa es completamente omisa, lo cual nos parece bastante grave, ya que crea inseguridad jurídica.

Por lo tanto, ante una evidente falta de técnica legislativa al respecto surgen dos interrogantes, a saber: ¿por qué se dejó de lado la materia mercantil?, y la segunda ¿por qué se incluyó la materia penal? Como ya se mencionó, la Ley Orgánica del Poder Judicial señala claramente, ${ }^{21}$ que el Instituto de Justicia Alternativa tendrá competencia para resolver controversias en materia civil, mercantil, familiar y penal, siempre y cuando "no se contravengan disposiciones de orden público o se trate de derechos irrenunciables y no afecten a terceros", ya sea a solicitud de las partes interesadas o que sean encomendados directamente por los órganos

20 Directiva 2008/52/CE del Parlamento Europeo y del Consejo del 21 de mayo de 2008 sobre ciertos aspectos de la mediación en asuntos civiles y mercantiles, párrafo 2 .

21 Artículo 176 de la Ley Orgánica del Poder Judicial del Estado de Chihuahua. 
Esta revista forma parte del acervo de la Biblioteca Jurídica Virtual del Instituto de Investigaciones Jurídicas de la UNAM www.juridicas.unam.mx https://biblio.juridicas.unam.mx/bjv DOI: http://dx.doi.org/10.22201/iij.24484881e.2017.37.11457

https://revistas.juridicas.unam.mx

jurisdiccionales. Lo más lógico es que la redacción normativa contemplara un artículo que señalara el ámbito de aplicación de la ley y sus limitaciones en los términos del artículo 176 de la Ley Orgánica del Poder Judicial, pero no lo hizo.

Ahora es importante recordar que tras la reforma constitucional del 18 de junio de 2008, en la que se modificó el sistema penal mexicano, ${ }^{22}$ como ya se apuntó, al artículo 17 se le adicionó el párrafo tercero, el cual señala: "Las leyes preverán mecanismos alternativos de solución de controversias. En la materia penal regularán la aplicación, asegurarán la reparación del daño y establecerán los casos en que se requerirá supervisión judicial" (énfasis añadido).

Lo cierto es que en el estado de Chihuahua, un par de años antes de dicha reforma, mediante decreto 693/06 I P.O., publicado en el Periódico Oficial del Estado Núm. 98 el 9 de diciembre de 2006, se expide la Ley de Justicia Penal Alternativa del Estado de Chihuahua, como parte del entonces llamado "nuevo sistema de procuración de justicia en materia penal", convirtiéndose así a nivel nacional en el primer estado que además de establecer el juicio oral, contaba con un Centro de Justicia Alternativa en materia penal incorporado a la entonces Procuraduría, ahora Fiscalía General del Estado de Chihuahua. ${ }^{23}$

La finalidad de la Ley de Justicia Penal Alternativa, según lo señala el artículo 1o. es: "Regular el procedimiento pre-procesal que se sigue en los Centros de Justicia Alternativa donde se aplican los medios alternos de solución de conflictos en materia penal, así como instituir la cumplimentación de los acuerdos reparatorios establecidos en el Título VII, Capítulo I, del Código de Procedimientos Penales". ${ }^{24}$

Nuevamente surge la pregunta, si desde el 2006 existe una Ley de Justicia Penal Alternativa y un Centro de Justicia Alternativa en materia

22 En dicha reforma constitucional publicada en el Diario Oficial de la Federación se modificaron los artículos 16, 17, 18, 19, 20, 21 y 22; el artículo 73, fracciones XXI y XXIII; el artículo 115, fracción VII, y la fracción XIII del apartado B del artículo 123.

23 Nájera, Horacio, "Aplica Chihuahua justicia alternativa", Periódico Reforma, México, 2 de enero de 2007.

24 Según lo establece el Código de Procedimientos Penales del Estado de Chihuahua en su artículo 196: "Se entiende por acuerdo reparatorio el pacto entre la víctima u ofendido y el imputado que lleva como resultado la solución del conflicto a través de cualquier mecanismo idóneo que tiene el efecto de concluir el procedimiento." El artículo 198 señala que: "Los acuerdos reparatorios procederán hasta antes de decretarse el auto de apertura al juicio oral”. 
Esta revista forma parte del acervo de la Biblioteca Jurídica Virtual del Instituto de Investigaciones Jurídicas de la UNAM

penal en el estado de Chihuahua, ¿por qué dar facultades en materia penal al recién creado Instituto de Justicia Alternativa? En otras palabras, ¿por qué tanto el Poder Ejecutivo como el Poder Judicial del Estado de Chihuahua, a través de sus respectivos órganos especializados, están ofreciendo a la ciudadanía servicios de justicia alternativa en materia penal de forma simultánea?

Está claro que uno de los objetivos de los ADR es garantizar un verdadero acceso a la justicia, al brindar al ciudadano una opción más para solucionar sus conflictos, sin embargo, estas facultades concurrentes en materia penal que tienen tanto el Centro de Justicia Alternativa como el Instituto de Justicia Alternativa del Estado de Chihuahua crea incertidumbre jurídica y confusión no sólo a la ciudadanía en general, sino a todos los posibles actores, es decir, abogados, autoridades institucionales, jueces, etcétera, además de otras implicaciones jurídicas.

\section{Mecanismos alternativos de resolución de conflictos en lo particular}

Cuando la Ley de Justicia Alternativa habla de los mecanismos alternativos de resolución de controversias en particular, ${ }^{25}$ señala a la mediación, conciliación y justicia restaurativa, sin especificar cuándo se aplicará uno y cuándo se utilizará otro.

No obstante, aquí la cuestión que nos gustaría destacar es que la normativa en comento se refiere a la justicia restaurativa como un mecanismo alternativo de resolución de conflictos y esto es incorrecto desde el punto de vista conceptual. ${ }^{26}$

De acuerdo al Manual sobre programas de justicia restaurativa de las Naciones Unidas, la justicia restaurativa tiene como objetivo primordial la reparación del daño para la víctima, la reinserción del infractor y el ser-

25 Artículos 5o. al 7o. de la Ley de Justicia Alternativa del Estado de Chihuahua.

26 Según Lode Walgrave, la justicia, en materia penal, se puede clasificar en retributiva, rehabilitadora y restaurativa, atendiendo al elemento en la que ésta se enfoca, siendo en la primera el crimen, en la segunda el delincuente y en la tercera la reparación del daño. Cabe destacar que cada tipo de justicia utiliza un modelo distinto, por ejemplo, la justicia retributiva usa el castigo ya que se enfoca en el crimen, la rehabilitadora emplea el tratamiento ya que se centra en el delincuente y la restaurativa el diálogo, porque su prioridad es la reparación del daño, Walgra, Lode, Restorative Justice and the Law, Reino Unido, Willan Publishing, 2002. 
Esta revista forma parte del acervo de la Biblioteca Jurídica Virtual del Instituto de Investigaciones Jurídicas de la UNAM

vicio a la comunidad. ${ }^{27}$ Ahora bien, este tipo de justicia se logra a través de procesos restaurativos, tales como la mediación, conferencias, círculos, paneles, etcétera. ${ }^{28}$

Es bien sabido que tradicionalmente la materia penal se había centrado exclusivamente en una justicia retributiva, basada en el castigo, sin embargo, gracias a las reformas constitucionales del 18 de junio de 2008, esto ha empezado a cambiar, ya que ahora, en algunos casos, se busca responder al comportamiento delictivo balanceando las necesidades de la comunidad, de las víctimas y de los delincuentes mediante la justicia restaurativa, ${ }^{29}$ la cual se puede definir de la siguiente manera:

...una corriente del derecho penal de intervención mínima que integra un conjunto de procedimientos voluntarios, flexibles y cooperativos en los que participan los protagonistas del conflicto penal, directa o subrogadamente uno o varios facilitadores y cuando resulta necesario los familiares, amigos, ciudadanos y representantes de instituciones públicas, privadas y sociales con el fin de atender las necesidades prosociales e intereses de la víctima, del delincuente y de la comunidad y de contribuir a su reintegración social para alcanzar la seguridad ciudadana, el orden público y la paz social. ${ }^{30}$

Para concluir con esta línea argumentativa, al analizar este concepto podemos distinguir claramente que en materia penal, la justicia restaurativa es el fin (consistente en la reparación del daño) y los mecanismos alternativos de resolución de controversias (mediación, conciliación, etcétera) son el instrumento para lograrlo.

\section{E. Aspectos procesales de la Ley}

Uno de los principios fundamentales para permitir el funcionamiento idóneo de los mecanismos alternativos de resolución de conflictos, a fin de

27 Organización de Naciones Unidas, "Manual sobre programas de justicia restaurativa", Oficina de las Naciones Unidas, Nueva York, 2006, p. 6.

28 Igartua, Irinea et al., Diccionario breve de justicia restaurativa. Una invitación interdisciplinaria e introductoria a sus conceptos, Alemania, Editorial Académica Española, 2012, p. 21.

29 Organización de las Naciones Unidas, op. cit., p. 6.

30 Buenrostro, Rosalia et al., Justicia alternativa y el sistema acusatorio, México, Secretaría Técnica del Consejo de Coordinación para la implementación del Sistema de Justicia Penal, 2012, p. 138. 
Esta revista forma parte del acervo de la Biblioteca Jurídica Virtual del Instituto de Investigaciones Jurídicas de la UNAM

asegurar un mejor acceso a la justicia, es la flexibilidad. Es un hecho que los procedimientos adaptados a las necesidades de la partes traen como resultado acuerdos exitosos en virtud de que en un alto porcentaje se cumplen de forma voluntaria y además que se preserva una relación amigable y viable entre las partes. ${ }^{31}$

En base a lo anterior, suponemos que a fin de garantizar una máxima flexibilidad en el proceso, la Ley de Justicia Alternativa del Estado de Chihuahua no trata aspectos procesales a profundidad, sino simplemente señala que: "Se observará el trámite previsto en la presente Ley, su reglamento y las demás disposiciones aplicables". ${ }^{32}$ Al respecto, la Ley únicamente se limita a establecer cómo se puede iniciar el procedimiento, a petición de parte o por derivación del juez, ${ }^{33}$ a dar facultades al Instituto para determinar si la controversia puede ser legalmente solucionable a través de los ADR y dedica algunos artículos al tema de convenios y acuerdos a los que podrían llegar las partes - forma, incumplimiento total y parcial, prescripción - y poco más. ${ }^{34}$ En relación al reglamento, que pudiera darnos más luz en cuanto al tema, cabe apuntar que a la fecha ${ }^{35}$ no se ha expedido alguno.

Ahora, si bien es cierto los procesos ADR deben ser sencillos, accesibles, efectivos, etcétera, a fin de cumplir su objetivo de proveer un acceso a la justicia para la población en general, también lo es que deben garantizar seguridad jurídica y procurar al máximo el respeto a los derechos fundamentales, el orden público y el interés general. ${ }^{36}$ Cabe destacar que a nivel internacional existen algunas importantes iniciativas supranacionales y de los Estados ${ }^{37}$ que coinciden sobre ciertos aspectos procesales básicos que toda normativa debe contemplar a fin de conceder a las partes dicha certeza jurídica y que desafortunadamente no encontramos en la Ley en análisis

\footnotetext{
31 Unión Europea, Directiva 2008/52/CE, op. cit., párrafos 3 y 5.

32 Artículo 32 de la Ley de Justicia Alternativa del Estado de Chihuahua.

33 Artículo 30 de la Ley de Justicia Alternativa del Estado de Chihuahua.

34 Artículos 35-38 de la Ley de Justicia Alternativa del Estado de Chihuahua.

35 Verano de 2015.

36 Vilalta, Esther, Mediación y arbitraje electrónicos, España, Arazandi, 2013, pp. 80 y 81 .

37 Entre dichas iniciativas destacamos a nivel internacional: Ley Modelo de la Comisión de Naciones Unidas sobre Conciliación Comercial Internacional; Ley Modelo de la Comisión de Naciones Unidas sobre Arbitraje Comercial Internacional; en España, Ley 5/2012, del 6 de julio, de Mediación en Asuntos Civiles y Mercantiles, entre otras.
} 
Esta revista forma parte del acervo de la Biblioteca Jurídica Virtual del Instituto de Investigaciones Jurídicas de la UNAM www.juridicas.unam.mx https://biblio.juridicas.unam.mx/bjv DOI: http://dx_doi.org/10.22201/iij.24484881e.2017.37.11457

https://revistas.juridicas.unam.mx

y que se deberían tomar en cuenta para la elaboración del reglamento que señala la normativa, tales como:

Prescripción. No existen en la Ley, disposiciones que indiquen si al iniciarse un procedimiento ADR, ya sea en instituciones públicas o privadas, se suspenden o interrumpen los plazos de prescripción que afectan la reclamación, objeto de la controversia.

Número y designación de facilitadores. De acuerdo con la Ley en análisis, el facilitador es el: "Especialista capacitado y certificado para conducir mecanismos alternativos para la solución de controversias, conforme a lo dispuesto en la presente ley". La normativa en comento no establece si pueden nombrarse uno o más facilitadores en un proceso ADR, tampoco si son las partes o las instituciones públicas o privadas responsables de la administración de los procedimientos, quienes pueden designarlo (s) o si éstos pueden ser recusados.

Sustanciación del procedimiento. Los procesos ADR deben centrarse completamente en el consenso y, por lo tanto, son los involucrados los que deben establecer la forma en que se dirimirá el conflicto. Sin embargo, la normativa no especifica si son las partes o las instituciones, públicas o privadas, quien determinará el cómo se desarrollará el procedimiento. Por ejemplo, tratándose de qué mecanismo alternativo se utilizará para la solución del conflicto, la Ley contempla la mediación y conciliación, ${ }^{38}$ pero, como ya se apuntó, no aclara cuándo se utilizará uno u otro.

Comunicación entre el facilitador y las partes. Con relación a este tema, la Ley estipula que estos procesos se desarrollarán: "En sesiones orales, conjuntas o individuales y se substanciarán de acuerdo con lo dispuesto en esta Ley, su reglamento y demás disposiciones aplicables", ${ }^{39}$ no aclara si deben de ser presenciales o permite que se realicen a través de medios electrónicos. ${ }^{40}$

Reiteramos, es indispensable incluir estos requisitos fundamentales de justicia procesal a fin de lograr una sustanciación equitativa y eficaz de los procedimientos ADR; a fin de dar certidumbre jurídica a las partes, sin

38 Quedó establecido, ya que la justicia restaurativa no se considera propiamente un mecanismo alternativo de resolución de conflictos, sino un fin que se alcanza a través de ellos.

39 Artículo 34 de la Ley de Justicia Alternativa del Estado de Chihuahua.

40 A pesar de la omisión de la Ley, el Instituto de Justicia Alternativa, que se encuentra en la capital del estado de Chihuahua, ha llevado a cabo tres procesos ADR, vía remota a través de Skype, enlazándose a Querétaro y los municipios de Ciudad Juárez y Parral. 
Esta revista forma parte del acervo de la Biblioteca Jurídica Virtual del Instituto de Investigaciones Jurídicas de la UNAM

perder de vista el principio de flexibilidad, estamos conscientes de que resulta una tarea compleja para el legislador, pero indispensable para lograr los objetivos de estos mecanismos, especialmente porque la Ley autoriza la creación de instituciones privadas, proveedoras de servicios ADR, cobijadas por esta Ley.

\section{F. Principio de confidencialidad}

Por último, el principio de confidencialidad constituye un pilar fundamental dentro de los procedimientos ADR, ya que permiten generar confianza en estos sistemas alternos, lo cual es indispensable para el éxito de los mismos. Sin embargo, existe cierta controversia en relación a la información y/o pruebas reveladas en estos procedimientos alternos, ¿hasta qué punto deben ser confidenciales? En otras palabras hablamos de una confidencialidad absoluta o con limitaciones.

En este caso, la ley claramente optó por una confidencialidad con restricciones, ${ }^{41}$ al establecer, en relación a la información derivada de un proceso ADR, que: "No podrá ser divulgada ni utilizada en procedimiento o juicio alguno, salvo que de los datos proporcionados se desprenda la probable comisión de un delito, en cuyo caso el facilitador lo comunicará al Ministerio Público para los efectos conducentes". ${ }^{42}$

Así, lo grave de esta limitante es que crea la facultad a los facilitadores de denunciar información que pudiera constituir un delito y de acuerdo con la propia normativa, los facilitadores, adscritos al instituto, no necesariamente deben ser licenciados en derecho, entonces pueden ser de cualquier profesión a fin a los ADR, ${ }^{43}$ es decir, psicólogos, trabajadores sociales, etcétera, surge la pregunta: si no son peritos en derecho, ¿cómo es que van a determinar la probable comisión de un delito derivada de la información de un proceso ADR en el que participen? Dar una facultad discrecional de esa magnitud, como limitante al principio de confidencialidad, consideramos que es bastante riesgoso simplemente por las consecuencias legales —como la posible violación a los derechos humanos - y otras implicaciones legales que pudiera acarrear.

41 Para más información sobre el tema, Restivo, James et al., "Confidential in Alternative Dispute Resolution (ADR)," Alternative to the High Cost of Litigation, vol. 2, núm. 5, pp. 5-10.

42 Ley de Justicia Alternativa del Estado de Chihuahua, artículo 11, fracción II.

43 Ibidem, artículo 25, fracción III. 
Esta revista forma parte del acervo de la Biblioteca Jurídica Virtual del Instituto de Investigaciones Jurídicas de la UNAM

Nuestra postura respecto del tema de la confidencialidad es que debería ser absoluta, e incluso ir más allá, es decir, establecer sanciones en caso de violación a este principio fundamental.

Desde nuestro particular punto de vista, en principio el producto acabado es una normativa confusa, contradictora, desordenada y con poca técnica legislativa; sin embargo, tiene algunos puntos fuertes a destacar, como el principio de la no discriminación. Ahora bien, resulta interesante determinar si las normas jurídicas en comento están siendo realmente efectivas en la práctica, es decir, si están cumpliendo con sus objetivos. ${ }^{44}$ Tal vez algunas estadísticas nos puedan dar luz al respecto. ${ }^{45}$

El Instituto de Justicia Alternativa, que se rige por la Ley en análisis, sólo de enero a junio de 2015 ha atendido un total de 1,920 asuntos en el estado de Chihuahua, ${ }^{46}$ de los cuales, 1,809 pertenecen al Distrito Judicial Morelos, uno de los más importantes en el estado, por lo que nos gustaría hacer especial referencia a él y presentar algunos datos interesantes: de los 1,809 atendidos en el Distrito Judicial Morelos, únicamente se abrieron 1,602 expedientes, de los cuales 1245 fueron por derivación externa y 357 por derivación interna. ${ }^{47}$ Asimismo, de estos 1,602 expedientes, 940 son del área civil, 324 de la materia familiar y 338 penales. Por último, de los 1,609 expedientes, 93 asuntos fueron concluidos por arreglo entre los usuarios sin convenio, 406 concluidos por convenio total, 9 concluidos por convenio parcial. En conclusión, el dato estadístico en el que nos gustaría poner un acento es el siguiente: uno de cada cinco expedientes que se abren en el Instituto llega a un acuerdo.

\section{REFLEXIONES FINALES}

Tras el decreto del 18 de junio de 2008 que reforma y adiciona diversos preceptos constitucionales, muchas cosas han cambiado en el tema de acceso a la justicia en México. Está claro que la intención de la Constitución

\footnotetext{
44 Afonso da Silva, José, Aplicabilidad de las normas constitucionales, México, UNAM, 2003, p. 52.

45 Estadísticas proporcionadas por la directora del Instituto de Justicia Alternativa, licenciada Lourdes Sigála Rodríguez (verano de 2015).

46 Asuntos tramitados en los distritos judiciales de Abraham González, Benito Juárez, Hidalgo, Morelos, del estado de Chihuahua.

47 Derivación externa se refiere a la solicitud oral o escrita de persona interesada, y derivación interna es a propuesta de un juez.
} 
Esta revista forma parte del acervo de la Biblioteca Jurídica Virtual del Instituto de Investigaciones Jurídicas de la UNAM

federal es garantizar que cada individuo tenga derecho a procesos eficaces y respetuosos de los derechos humanos, a fin de obtener de manera pronta y certera justicia de calidad a la hora de solucionar sus conflictos. En este sentido, los ADR buscan convertirse en mecanismos de tutela idóneos que permitan llevar al plano de la realidad las prescripciones constitucionales en la materia.

Así, la respuesta de las entidades federativas en relación al mandato constitucional de implementar mecanismos alternativos de solución de conflictos ha sido muy positiva, en virtud de que se han expedido leyes y creado instituciones proveedoras de estos servicios en prácticamente todo el país. Sin embargo, a casi una década de la reforma constitucional de 2008, los ADR aún no han logrado consolidarse en México de la forma esperada.

Como ya se expuso con anterioridad, el presente artículo hace un análisis de la Ley de Justicia Alternativa del Estado de Chihuahua, como caso de estudio, a fin de determinar si la Ley está a la altura de las expectativas constitucionales. Tomando como base el análisis de la normativa, consideramos que dicha Ley no ofrece novedades conceptuales, procedimentales o sustanciales en la materia y que la forma en que regula los mecanismos alternativos de solución de conflictos no está a la altura de la tendencia internacional.

Con todo, no creemos que la Ley sea completamente negativa, en conjunto las disposiciones de la normativa demuestran un esfuerzo importante por implementar los ADR y ofrecer así a la población una opción simple, económica y eficaz de resolver sus conflictos, con miras de cambiar el paradigma de acceso a la justicia en el estado y por ello en el país. Asimismo, las estadísticas que presenta el Instituto de Justicia Alternativa del Estado de Chihuahua resultan bastante alentadoras, en poco tiempo han logrado que la población los tome en cuenta como una opción confiable para resolver sus conflictos, siendo esto un gran avance. Además, los acuerdos alcanzados demuestran que las personas pueden resolver sus controversias, sin intervención de una autoridad jurisdiccional, únicamente con la ayuda de un facilitador que les proporciona las herramientas necesarias para lograrlo.

Sin embargo, definitivamente aún queda mucho camino por recorrer. Así, en primer término, un replanteamiento de pensamiento por parte de las y los juristas sobre el papel de los ADR en la impartición de justicia ayudaría bastante, ya que sus reservas en relación a estos mecanismos 
Esta revista forma parte del acervo de la Biblioteca Jurídica Virtual del Instituto de Investigaciones Jurídicas de la UNAM

alternos de justicia hacen que la consolidación de estos sistemas sea muy complicada; pero más importante, un cambio de paradigma de tal envergadura relacionado al tema de acceso a la justicia y los mecanismos alternativos de resolución de conflictos, contemplado por la Constitución como derecho humano, definitivamente requiere de estrategias y acciones adecuadas y eficaces por parte de las autoridades responsables, a fin de garantizar que las nuevas disposiciones alcancen los fines para los cuales han sido diseñadas, en el caso de la Ley de Justicia Alternativa del Estado de Chihuahua: "fomentar y difundir la cultura de la paz y restauración de relaciones interpersonales y sociales". ${ }^{4}$

\section{BIBLIOGRAFÍA}

AfOnso DA Silva, José, Aplicabilidad de las normas constitucionales, México, UNAM, 2003.

BARONA, Silvia, Solución extrajurisdiccional de conflictos y derecho procesal, Valencia, Tirant lo Blanch, 1999.

BARRET, Jerome, A History of Alternative Dispute Resolution: the Story of a Political, Cultural and Social Movement, Estados Unidos, JosseyBass, 2004.

BUENROSTRO, Rosalía et al., Justicia alternativa y el sistema acusatorio, México, Secretaría Técnica del Consejo de Coordinación para la Implementación del Sistema de Justicia Penal, 2012.

Estalvillo, Fernando, Medios alternos de solución de controversias, México, Porrúa, 2004.

GONZÁLEZ, Nuria, "Un acercamiento al acceso a la justicia a través de la mediación como medio alterno de solución de conflictos", en FLORES, Elvia (comp.), Sin derechos, exclusión y discriminación en el México actual, México, UNAM, Instituto de Investigaciones Jurídicas, 2014.

GORJÓN, Francisco, "Implementación de las reformas al artículo 17 constitucional en materia de MASC en México y Panamá”, Letras Juridicas, núm. 11, 2010.

y PesqueIRA, Jorge, La ciencia de la mediación, México, Tirant lo Blanch, 2015.

48 Artículo 2o., fracción I, de la Ley de Justicia Alternativa. 
Esta revista forma parte del acervo de la Biblioteca Jurídica Virtual del Instituto de Investigaciones Jurídicas de la UNAM www.juridicas.unam.mx https://biblio.juridicas.unam.mx/bjv https://revistas.juridicas.unam.mx

NÁJERA, Horacio, “Aplica Chihuahua justicia alternativa,” Reforma, México, 2 de enero de 2007.

IGARTUA, Irinea et al., Diccionario breve de justicia restaurativa. Una invitación interdisciplinaria e introductoria a sus conceptos, Alemania, Editorial Académica Española, 2012.

MONDRAGÓN, Fabián, "Justicia alternativa en materias civil, mercantil y familiar”, en FERrER, Eduardo (comp.), Procesalismo científico. Tendencias contemporáneas, México, UNAM, Instituto de Investigaciones Jurídicas, 2012.

RAMOS, Fernando, Medidas alternativas a la resolución de conflictos por la vía judicial en el ámbito civil patrimonial, España, Bosch, 1981.

RESTIVO, James et al., "Confidential in Alternative Dispute Resolution (ADR)," Alternative to the High Cost of Litigation, vol. 2, núm. 5, 2009.

SingER, Linda, Resolución de conflictos, Buenos Aires, Paidós, 1981.

VARGAS, Juan, "Problemas de los sistemas alternos de resolución de conflictos como alternativa de política pública en el sector judicial," Anales de Jurisprudencia, vol. 264, 2003.

VilALTA, Esther, Mediación y arbitraje electrónicos, España, Arazandi, 2013.

WALGRA, Lode, Restorative Justice and the Law, Reino Unido, Willan Publishing, 2002.

Fecha de recepción: 12 de enero de 2016.

Fecha de dictamen: 22 de marzo de 2017. 